ISSN: 2349-2031

https://valleyinternational.net/index.php/theijsshi

Research Article

\title{
The Profession of Producing Green Rice Flakes (Cốm) in Me Tri Thuong Village, Me Tri Ward, Nam Tu Liem District, Hanoi, Vietnam
}

\author{
Nguyen Thi Hai Yen ${ }^{1}$, Dao Thi Luu ${ }^{1}$, Phi Thi Thu Hoang ${ }^{1}$, Le Thi Hanh Lien ${ }^{1}$ \\ Institute of Geography, Vietnam Academy of Science and Technology \\ 18 Hoang Quoc Viet street, Cau Giay district, Hanoi, Vietnam
}

\begin{abstract}
Abtract
Producing green rice flakes (it's called Cốm in Vietnam) is classified as one of the oldest traditional professions of formerly and present Hanoi. It has been preserved for generations and plays an important part in the diverse and flavorful cuisine of Hanoi. In Hanoi, there are two villages which is famous for making green rice flakes: Me Tri in Nam Tu Liem district (including Me Tri Thuong, Me Tri Ha village) and Vong village in Cau Giay district. The profession of making green rice flakes in Me Tri up to now has a history of more than a century. Experiencing many ups and downs, the profession of making green rice flakes of Me Tri ward in general, and of Me Tri Thuong village in particular, still exists, develops and has changed a lot. In the past, every year the villagers only made green rice flakes in one crop, then added the fifth-month crop but now they make it all year round. On the other hand, instead of making green rice flakes entirely by hand, local people in this village nowadays have used machines and mechanized the stages of making green rice flakes, which help saving time, reducing production costs but still ensuring quality. The production process of green rice flakes is quite complicated, including many stages that require meticulousness, ingenuity and accuracy of the makers. The products made of green rice flakes are also diverse. Those are the specialties not only of Me Tri and Hanoi, but also recognized as an indispensable part of Vietnamese culinary culture. Me Tri green rice flakes (Cốm Mễ Trì) are now not only consumed domestically, but also exported to foreign countries such as the UK, Japan, the US and become favorite gifts for international tourists. Therefore, the profession of making green rice flakes in Me Tri in general and Me Tri Thuong in particular is really a unique cultural tourism resource that needs to be preserved and is a strength for the development of craft village tourism.
\end{abstract}

Keywords: traditional profession, profession of making green rice flakes, production process of making green rice flakes, Me Tri Thuong.

\section{Introduction}

Up to now, traditional crafts still play a very important role in the economic life of people in our country. Besides economic and social values, cultural and spiritual values are the most outstanding ones of traditional crafts. Traditional handicraft products are not only purely economic goods but also creative and artistic products. They reflect the customs, practices and beliefs of the ethnic communities in our country. In recent years, the social context has changed a lot, and the trend of commercialization has also affected traditional crafts. Many traditional crafts in localities across the country in general and the profession of making green rice flakes in Me Tri in particular are gradually being lost, and there is a shortage of people to inherit and develop this profession.

Me Tri ward consists of two villages, Me Tri Thuong and Me Tri Ha, in Nam Tu Liem district, on the outskirts of Hanoi. Its population in 2020 was about 27,000 people with a total natural area of $4.67 \mathrm{~km}^{2}$. The profession of making green rice flakes was imported to Me Tri more than 100 years ago and is a 


\section{Nguyen Thi Hai Yen et. al/ The Profession of Producing Green Rice Flakes (Cốm) in Me Tri Thuong Village, Me Tri Ward, Nam Tu Liem District, Hanoi, Vietnam}

traditional profession that brings high income to households in these two villages [1]. Along with Vong village (Cau Giay), Me Tri green rice flakes is a speciality not only of Me Tri village but also of Hanoi. Me Tri's green rice flakes profession with a long tradition still retains the secret of making that can't be found anywhere else. Me Tri green rice flakes has been affirmed and become the famous and elegant gifts of Hanoians in particular and of Vietnamese in general.

In order to continue to preserve, develop the profession of making green rice flakes in Me Tri and turn it into unique and attractive tourism products, it is necessary to have specific research on this traditional profession and find a suitable direction to develop the economy and preserve the culture of the locals here.

\section{Material And Methods}

\section{Field trip}

We had a direct survey in Me Tri Thuong village, Me Tri ward, Nam Tu Liem district, Hanoi in July 2021.

\section{Interview}

In order to implement this article, we directly interviewed the local people and visited the green rice flakes factory of the households in Me Tri Thuong village, Me Tri ward, Nam Tu Liem district, Hanoi.

\section{Other resources}

We consulted the following documents:

- Nam Tu Liem district in general, Me Tri Thuong village in particular: Shifting labor structure of rural households (in the case of Me Tri ward, Tu Liem district, Hanoi); Decision No. 446/QD-BVHTTDL on the proclamation of the National Intangible Cultural Heritage List.

- Hanoi People's Committee: Report on approving the master plan on development of professions and craft villages in Hanoi up to 2020 and orientation to 2030; Rural industry development plan in Hanoi in 2021.

\section{Results And Discussion}

\section{Ingredients and tools for making green rice flakes in Me Tri Thuong village \\ 1.1. Ingredients}

Me Tri Thuong green rice flakes is usually made from young sticky rice. When pressing on the grain of rice with fingernal, the milk layer of rice come out. That is the time for young sticky rice. Old sticky rice are used to make other products. There are many kinds of sticky rice that can be made into green rice flakes such as brown sticky rice, velvet glutinous rice,... but the best one is still yellow flower sticky/glutinous rice (Nếp cái hoa vàng). Since this is a type of sticky rice with characteristics of fragrance, softness, and sweetness, it produces more delicious finished products than others. Yellow flower glutinous rice is grown in both seasons: February to March and the full moon of July to the end of September (the lunar calendar). In the past, when there were still many rice fields, the local people used to grow rice themselves to make green rice flakes. However, due to urbanization nowadays, the sticky rice fields in Me Tri have been narrowed and are not enough to meet the needs of making green rice flakes, so Me Tri Thuong households have to import sticky rice from other suburban districts such as Thach That, Soc Son, Ung Hoa, Dong Anh or neighboring provinces such as Bac Ninh, Bac Giang, Vinh Phuc... They often buy the whole field and hire farmers to take care and harvest green rice. There are households who even bring yellow flower glutinous rice varieties from their villages and wards to other localities to hire them planting with the aim of improving green rice flakes' products from the famous sticky rice variety of Me Tri. They also set strict requirements for rice caregivers such as no using stimulants as well as using sufficient pesticide residues... The thing that made the previous difference between Me Tri Thuong green rice flakes in particular, Me Tri in general and Vong village's green rice flakes is the ingredients. Since Me Tri green rice flakes are made from fifth-month rice, the grains are thinner, softer, and more fragrant than Vong village's green rice flakes. Moreover, Me Tri green rice flakes is completely rustic without using colouring products, so it has created a unique flavor of Me Tri.

\subsection{Green rice flakes making tools}




\section{Nguyen Thi Hai Yen et. al/ The Profession of Producing Green Rice Flakes (Cốm) in Me Tri Thuong Village, Me Tri Ward, Nam Tu Liem District, Hanoi, Vietnam}

In the past, Me Tri green rice flakes were mainly made by human labor power. This process was very hard with many stages and people needed, but the income was not high. According to our interview results, starting from the first stage, the owner of the establishment must hire the elderly (more than 10 people) in the village to cut and select the sticky rice, then bring to winnow and remove the imperfect grains. Then, the next processes require at least 3 people to carry out the stages of roasting green rice flakes and sieving them by hand in a mortar and pounding them using feet. However, by the end of 2000, Me Tri Thuong 's green rice flakes making profession had started to apply machines and technology to some stages of making green rice flakes, and so far, almost mechanized the whole process of producing green rice flakes. Using machines help to reduce labor and increase the amount of products but still keep the delicious taste compared to craft products.

Although the current production of green rice flakes is supported by many mechanized devices to shorten the processing time, most of the stages of making green rice flakes are still carried out manually and sophisticatedly. Machines cannot completely replace the labor of workers. From threshing to washing the rice, choosing perfect grains to roast, controlling the fire, pounding the green rice flakes..., all the processes require experience and skillful hands of the workers. During the rice season, each family may need 5 to 6 people to work together, and on weekdays, there must also be 2 workers involved, especially in the stage of roasting and winnowing the green rice flakes.

Table 1: Ingredients and tools used in green rice flakes production process

\begin{tabular}{|c|l|l|}
\hline \multirow{4}{*}{ Ingredients } & \multicolumn{2}{|c|}{ Glutinous rice } \\
\hline \multirow{5}{*}{ Tools } & Craft products & Mechanized products \\
\cline { 2 - 3 } & Threshing by hand & Threshing machine \\
\cline { 2 - 3 } & Bamboo sieve & Paddy separater machine \\
\cline { 2 - 3 } & A large firing pan & Electric pan \\
\cline { 2 - 3 } & Mill mortar (for hand using) & Rice milling machine \\
\cline { 2 - 3 } & Rice mortar (for feet using) & Rice pounding machine \\
\cline { 2 - 3 } & $\begin{array}{l}\text { Lotus leaves, phrynium } \\
\text { leaves }\end{array}$ & $\begin{array}{l}\text { Lotus leaves, tiger grass leaves (lá đót), phrynium leaves (lá } \\
\text { ráy) }\end{array}$ \\
\hline
\end{tabular}

Source: Summarized survey [2]

\section{The production process of green rice flakes in Me Tri Thuong village}

In order to produce products from grains of rice to green rice flakes and other finished products, there are many different stages that need to be processed. Each stage has its own tools and techniques that require the meticulousness and experience of the workers. A basic production process of green rice flakes includes these four following stages: harvesting and sifting rice; roasting green rice grains; milling and pounding green rice flakes and packaging.

\subsection{Harvesting and sifting rice}

Households in Me Tri Thuong village usually rent the places where they directly transplant, harvest and sift rice. They buy the whole fields when the rice is still green or deliver rice seeds there and hire farmers to transplant, then monitor the process until the rice is ready to be harvested.

When the rice is harvested, the local people will reap, thresh and sift the rice themselves. They then remove the imperfect seeds by placing the rice in the water tank. Floating seeds will be removed, then the sink seeds will be brought out to dry. They bagged and transported it to the people who make green rice flakes in $\mathrm{Me}$ Tri Thuong. The harvested grains of rice must be used to make young green rice flakes during the day. Among them, young green rice must be processed during the day because if it is left overnight, it will no longer have sweet and good taste, while old green rice can be left to the next day. 


\section{Nguyen Thi Hai Yen et. al/ The Profession of Producing Green Rice Flakes (Cốm) in Me Tri Thuong Village, Me Tri Ward, Nam Tu Liem District, Hanoi, Vietnam}

\subsection{Roasting green rice grains}

This is the most important and longest stage of the green rice flakes production process and also the most difficult stage for the workers. The green rice flakes become soft and delicious or not is dependent on this stage.

The glutinous rice grains after being winnowed are then divided into batches and put in a roasting pan placed on the stove. The stove for roasting green rice grains must be covered with coal slag, but the coal is not the one to be burned, only the firewood. The roasting pan is often ordered by local people with cast iron. This kind of roasting pan has enough thickness so that when green rice grains are roasted, they are evenly cooked, not burnt, and able to keep the soft, smooth and fragrant feeling. Normally, a batch of green rice grains will be roasted from 1.5 to 2 hours. The worker who does this stage must be a person with a lot of experience and skills. They always have to pay attention to control the fire and make sure the green rice grains are roasted well to avoid being unwell cooked and put water in the firing pan at the right times. According to workers' experience, the batch of roasted rice is only achieved when we pick up the rice by hand at any position in the pan to check, the young rice grains must be slightly twisted, and the old rice grains when ripe must reach the sticky level. This work needs high precision because too young toasted green rice grains will be too sticky, a little old roasted green rice grains will dry leading to spoilage of the whole batch of green rice flakes. Towards the end of this stage, the workers have to check the roasted green rice grains regularly by averaging every 30 seconds. Unroasted rice is green, after roasting, it turns yellow or slightly white, fragrant, and the husk is peeled off.

\subsection{Milling and pounding green rice flakes}

The rice after being roasted, is brought out for cooling down and then peeled. Although the rice milling machine takes over this process, it still requires labor to avoid the green rice flakes from being stuck in the machine. This stage also has to be extremely meticulous so that the young rice flakes are green, smooth, sticky and keep their flavor well.

Depending on the type of rice (young or old), the workers can decide to do heavy or light pounding as well as doing more or less number of pounding times. Usually, on average, pounding and sieving need to be processed repeatly from 3 to 5 times to form perfect green rice flakes. Grains of rice with husk are pounded in batches depending on the diameter and depth of the rice pounding machine. The green rice flakes are pounded evenly, then remove all the husks found and continue the pounding and sifting process again until the husks is completely take off and the green rice flakes are soft. A batch of about $10 \mathrm{~kg}$ of young glutinous rice will be able to create about $2 \mathrm{~kg}$ of green rice flakes. Producing a batch of $40-50 \mathrm{~kg}$ of green rice flakes normally takes about 3 to 4 hours. The workers often put the batch of young green rice flakes with the most delicious flavor and sticky feeling on top to sell it at a higher price.

\subsection{Packaging}

Finished green rice flakes after cleanly sieving are packed in 2 layers of leaves. The inner layer is tiger grass leaves or phrynium leaves - types of leaf that retains water, so it keeps the moisture for the green rice flakes to be soft and do not fade into turquoise color. Leaves are all bought in Phu Do village, Nam Tu Liem district. The outer layer is lotus leaves, which symbolizes purity. Moreover, lotus leaves have a fragrance that helps to create a special flavor for the green rice flakes. Lotus leaves are imported by Me Tri Thuong people from Hue in large quantities, from one to two quintals each time. The green rice flakes are then tied with green wheat straw.

Overall, the production process of green rice flakes consists of many complicated stages, each stage requires the workers to work with enthusiasm and give a great love for their job. 


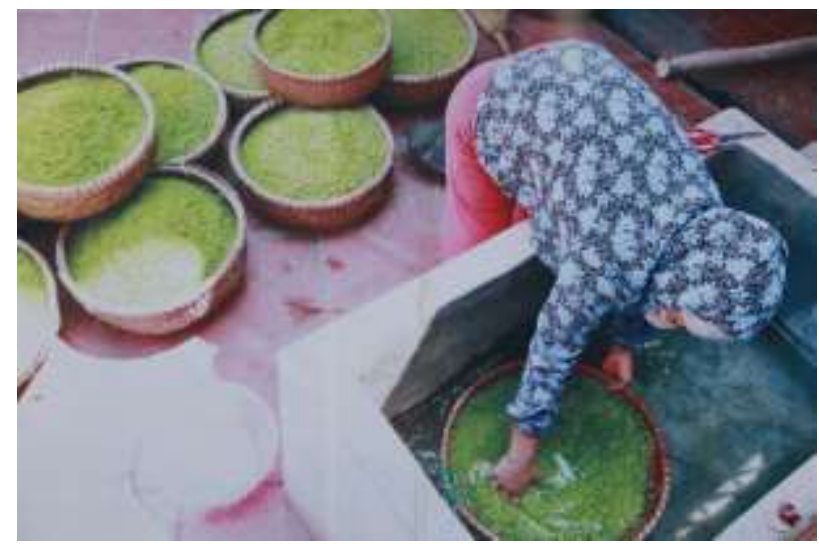

Figure 1: Sifting rice (Source: Internet)

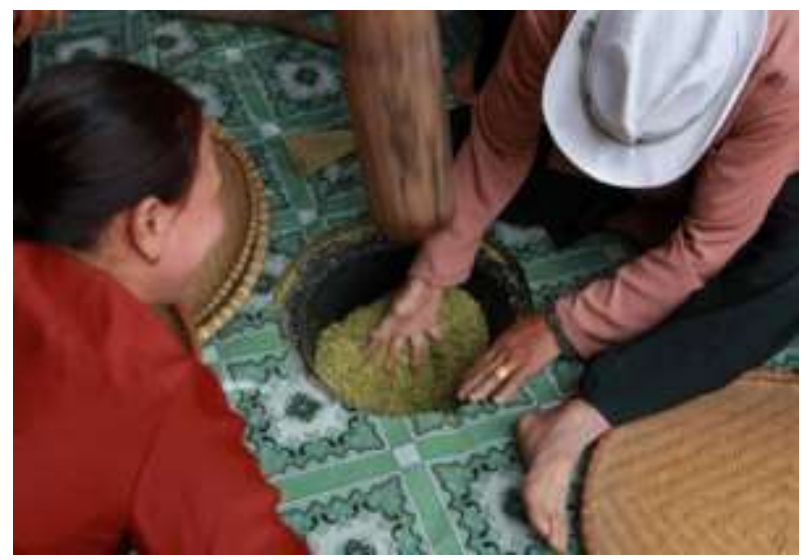

Figure 3: Pounding green rice flakes

(Source: Internet)

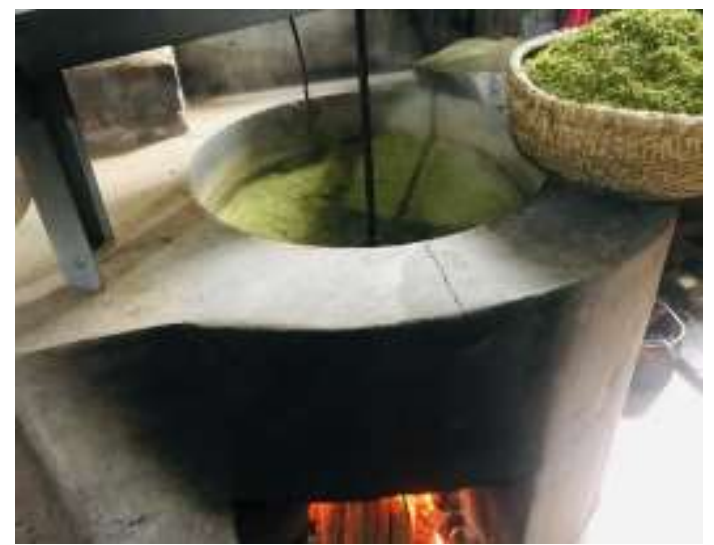

Figure 2: Roasting green rice grains

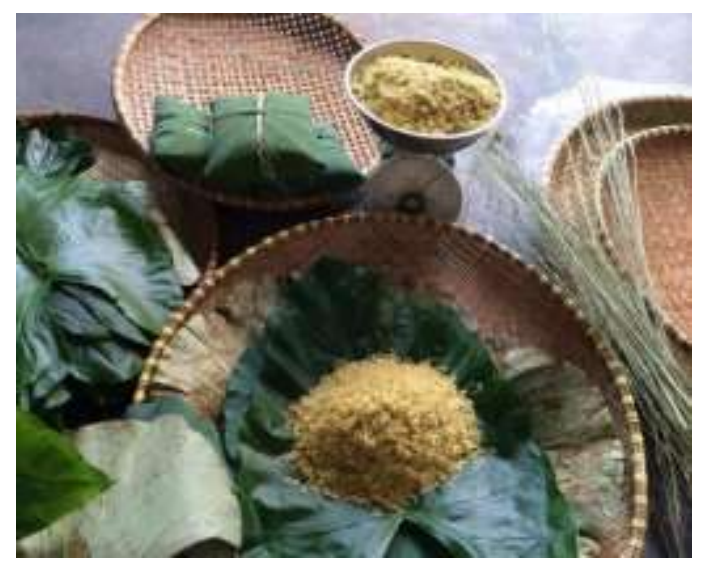

Figure 4: Packaging

(Source: Internet)

\section{Finished products from green rice flakes}

Depending on the maturity of the glutinous rice grains, different green rice flakes products are produced. Young green rice at the beginning of the season with thin and soft seeds often used to make granulated green rice flakes suitable for vegetarians or eaten with aromatic banana. Dry roasted green rice flakes are not as delicious as fresh green rice flakes, but in return they can be preserved for a long time and are easy to deliver. The mid-season green rice are usually used to make green rice with minced pork (Chả cốm), green rice sausages (Xúc xích cốm), fried green rice (Cốm xào), etc. The late-season green rice are big and thick seeds that are a bit hard to eat, suitable for cooking sweet soup, ice cream, or green sticky rice.

Each finished product has its own way of cooking and mixing with a certain percentage. For example, green rice with minced pork and green rice sausages are made from 7 parts of meat and 3 parts of green rice and spices, then steamed. Lotus seed and coconut sticky rice (Xôi cốm sen dìa) is made with fresh green rice mixed with green beans, coconut cream and lotus seeds imported directly in Hue (due to the fragrant and round seeds). Lotus seed and coconut sticky rice is usually sold on the 1st and 15th of the lunar month. Green rice cake is also made from the main ingredients of fresh green rice with green beans, coconut cream, grated coconut, sugar, pumpkin jam and grapefruit flower flavor. Green rice cakes are often used as gifts in festivals and weddings.

The green rice flakes need to be carefully preserved, avoiding dry weather to keep the plasticity and fragance. The same goes for other products, depending on the time of use. For example, green rice cake can only be used within 3 to 5 days; green rice with minced pork or green rice sausages need to be kept in the refrigerator for 5-7 days or frozen for 2 months. Particularly, the green sticky rice must be eaten during the day. 


\section{Nguyen Thi Hai Yen et. al/ The Profession of Producing Green Rice Flakes (Cốm) in Me Tri Thuong}

Village, Me Tri Ward, Nam Tu Liem District, Hanoi, Vietnam

The waste products from the process of making green rice flakes are utilized to the fullest extent for many different purposes such as making green rice wine or raising chickens and ducks; selling rice husks to peach and kumquat gardens.
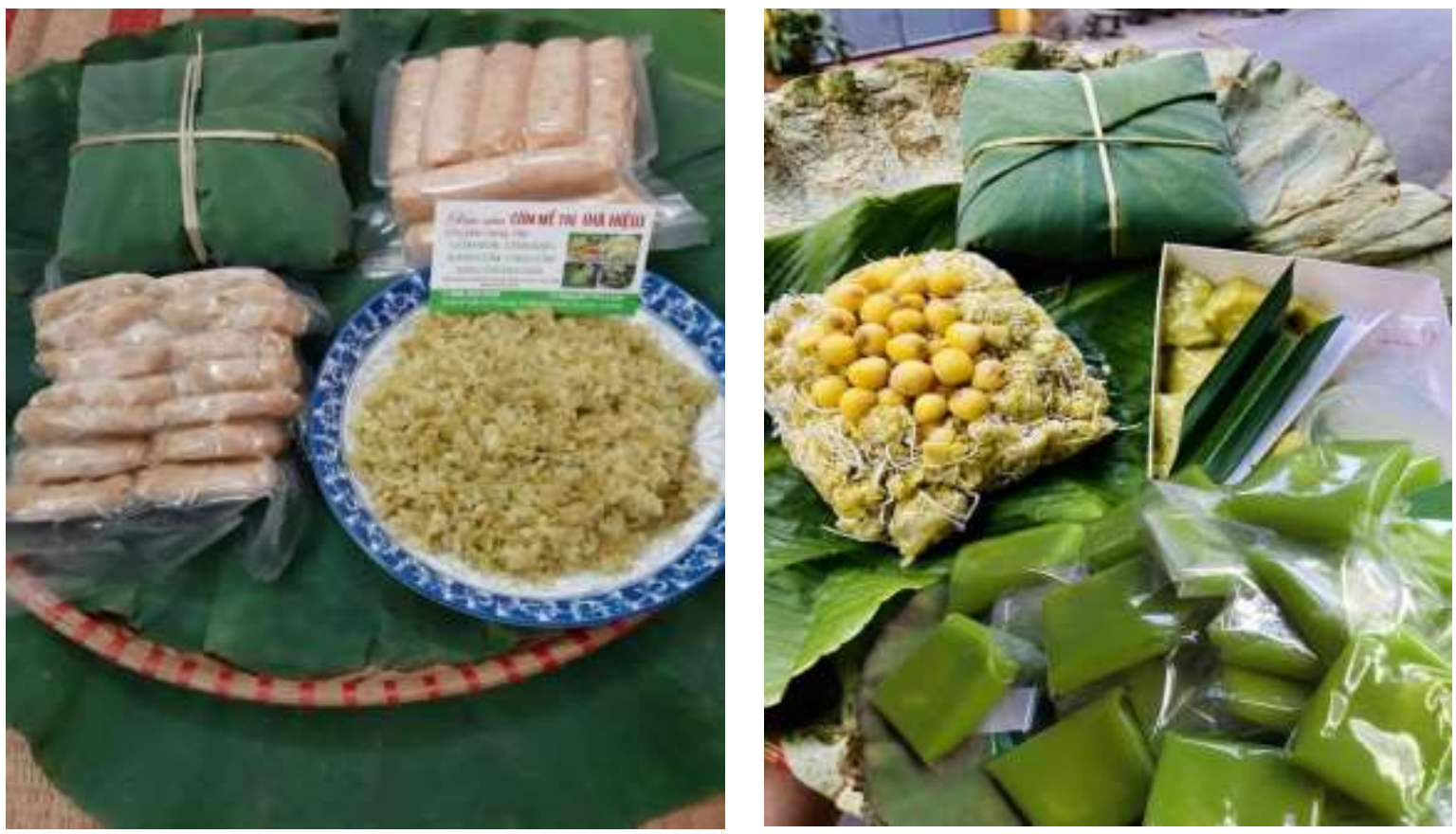

Figure 5,6: Products made from green rice flakes (Source: Interview)

4. Current status of developing the profession of making green rice flakes in Me Tri Thuong village. 4.1. Current status of green rice flakes production in Me Tri Thuong village

Me Tri green rice flakes are a long-standing traditional profession of Hanoi people, each household usually has 3 to 5 generations following the profession. Before the 2000s, almost $100 \%$ of the households in Me Tri made green rice flakes. In the period of 2000-2018, the whole ward had more than 300 households working in this profession. By 2019, there are about 50 households, of which Me Tri Thuong accounts for about 50\% (with more than 20 households) and in 2020 there are only about 20 households in the ward still following the profession, and Me Tri Thuong village also has only 7 to 8 households $[2,3]$.

In the past, when it was still manual production, about 10 workers worked day and night on average, producing 15 to $18 \mathrm{~kg}$ of green rice flakes. Nowadays when combining machines into production stages, it only takes 3 to 5 workers from 4 am to $9 \mathrm{pm}$ to produce an average output of over $60 \mathrm{~kg} / \mathrm{day}$. The market is stable, the wholesale and retail prices are high due to the well sale of products, leading to high incomes of the residents. However, since the end of 2019, due to the appearance of the Covid-19 epidemic, the production output as well as the revenue from selling green rice flakes, both wholesale and retail, have decreased by half compared to the time when the epidemic did not appear. The average daily amount of income also decreased significantly [Table 2].

Table 2: Production and consumption of green rice flakes before and during the Covid epidemic of production factory.

\begin{tabular}{|l|l|c|c|}
\hline \multirow{2}{*}{ No } & \multirow{2}{*}{ Criteria } & \multicolumn{2}{|c|}{ Time } \\
\cline { 3 - 4 } & & Before 2020 & From early 2020 until now \\
\hline $\mathbf{1}$ & Production & $70-80 \mathrm{~kg} / \mathrm{day}$ & $30-40 \mathrm{~kg} / \mathrm{day}$ \\
\hline $\mathbf{2}$ & Consumption & $70-75 \mathrm{~kg} / \mathrm{day}$ & $20-30 \mathrm{~kg} / \mathrm{day}$ \\
\hline $\mathbf{3}$ & Revenue & & \\
\hline 3.1 & Retail price & $200,000-250,000 \mathrm{VND} / 1 \mathrm{~kg}$ & Under $170,000 \mathrm{VND} / 1 \mathrm{~kg}$ \\
\hline
\end{tabular}




\section{Nguyen Thi Hai Yen et. al/ The Profession of Producing Green Rice Flakes (Cốm) in Me Tri Thuong Village, Me Tri Ward, Nam Tu Liem District, Hanoi, Vietnam}

\begin{tabular}{|c|l|c|c|}
\hline 3.2 & Wholesale price & $120,000-150,000 \mathrm{VND} / 1 \mathrm{~kg}$ & $90,000-110,000 \mathrm{VND} / 1 \mathrm{~kg}$ \\
\hline 3.3 & $\begin{array}{l}\text { Average income/day } \\
\text { in the main season }\end{array}$ & $400,000-500,000 \mathrm{VND} / \mathrm{day}$ & $200,000-300,000 \mathrm{VND} /$ day \\
\hline 3.4 & $\begin{array}{l}\text { Average income/day } \\
\text { off-season }\end{array}$ & $200,000-300,000 \mathrm{VND} /$ day & Under 200,000 VND/day \\
\hline
\end{tabular}

Source: Summarized survey (1 USD $\approx 23,134$ VND)

Currently, finished products from green rice flakes are made and sold all year round thanks to the use of freezers. Households making green rice flakes on a small scale usually have 3 to 5 freezers, while those working on a larger scale have up to 10 freezers for the purpose of storing green rice flakes for year-round use. In the main season, fresh green rice flakes are made a lot, both sold and stored in the freezers. Fresh green rice flakes are wrapped in lotus leaves, then frozen. When you need to eat or use green rice flakes to make other products, you only need to take them out for about 30 to 40 minutes, then pound them again. The green rice flakes will be fresh again, soft and smooth without losing its characteristic smell. However, according to science, when the green rice flakes are stored in the freezer at too low temperature, the starch structure is separated, which change the nutritional composition, so the frozen green rice flakes are no longer as nutritious as the new green rice flakes.

The green rice flakes consumption market of production facilities is mainly wholesalers in all three regions of the North, Central and South of Vietnam. The nearest is Bac Giang, further is Nghe An, Ha Tinh and then Ho Chi Minh City. Retailers are usually few but give high prices, mainly focusing on the Hanoi market. In addition, $100 \%$ pure green rice flakes are also sold as ingredients for some food companies. They use green rice flakes to preliminarily process into canned products and then sell them to pharmaceutical companies for medicinal use.

\subsection{The value of products from green rice flakes in Me Tri Thuong village}

Since Hanoi has Vong village's green rice flakes in Cau Giay district, so few people know about Me Tri green rice flakes before. Only in recent years, when the awareness of the brand has increased, the local authorities as well as the people made efforts to affirm the value of Me Tri green rice flakes.

One of the outstanding activities is the organization of the first "Me Tri green rice flakes festival" in 2012. Here, visitors can immerse themselves in the ancient space of a village on the edge of Hanoi with a unique traditional craft. During the festival, many cultural activities took place such as re-enacting the scene of making green rice flakes; displaying and introducing Me Tri green rice flakes; organizing competition and culinary introducing about green rice flakes; re-enacting Me Tri green rice flakes night market; organizing a beautiful photo contest about Me Tri green rice flakes; ... Besides, the visitors also had the opportunity to learn and enjoy delicious and special dishes from green rice flakes such as: green rice cake, green rice sweet soup, green sticky rice, green rice with minced pork, green rice wine, etc. Since then, this event has become an annual cultural activity which attracts a large number of visitors.

Currently, Me Tri has established the Me Tri green rice flakes association to gather the green rice flakes making households of Me Tri ward in general, and the households of Me Tri Thuong in particular during the crop season. In order to encourage households to maintain and expand the profession of making green rice flakes and help them promote their products, local authorities have implemented many practical support policies. Typically, the support to grant Certificate of Food Hygiene and Safety to establishments producing and trading in green rice flakes; awarding Certificates of Merit to families who preserve and promote the traditional green rice flakes making profession. When organizing the fair, the association bring the best conditions to each green rice flakes making household to have a free booth to promote and sell their products.

In 2016, Me Tri traditional craft village was honored to become one of the 5 craft villages which were approved by the Hanoi People's Committee to recognize the title of "Hanoi Traditional Craft Village"[4] and was visited by the US President during his official visit to Vietnam. In 2018, Me Tri Thuong green rice flakes appeared at the Hanoi food culture festival taking place at Thong Nhat park. Especially at the 


\section{Nguyen Thi Hai Yen et. al/ The Profession of Producing Green Rice Flakes (Cốm) in Me Tri Thuong Village, Me Tri Ward, Nam Tu Liem District, Hanoi, Vietnam}

beginning of 2019, during the DPRK-USA Hanoi Summit Vietnam, green rice flakes and other Me Tri's green rice products were also honored to be selected by the Central Government and Hanoi as one of the nine quintessential specialties of Hanoi to introduce and serve delegates as well as domestic and international media at the Press Center. On March 29, 2019, Me Tri profession of making green rice flakes were honored to receive the National Intangible Cultural Heritage Certificate [5]. It can be said that this is a great pride for the local authorities and people of Me Tri, which at the same time affirms the value of this heritage in the culture and cuisine of Hanoi capital.

\section{Advantages and disadvantages in developing the profession of making green rice flakes in Me Tri Thuong village.}

Currently, Me Tri profession of making green rice flakes are developing strongly and having great changes, playing an important role in the economic and cultural development of Me Tri. Recognized as a National Intangible Cultural Heritage, Me Tri's green rice flakes making profession are having new advantages and opportunities, but there are also many challenges and difficulties that need to face in terms of conservation and development.

Me Tri Thuong village, Me Tri ward, Nam Tu Liem district is located on the outskirts of Hanoi city, which is more than $10 \mathrm{~km}$ from the center of Hanoi. Being in the position of a craft village located in the city - an economic, cultural and political center of the country, it is the most favorable condition for the development of the green rice flakes industry. In addition to the achievements achieved in the previous years, at present, the profession of making green rice flakes in Me Tri Thuong is still one of the professions that the People's Committee of Nam Tu Liem District is interested in and supports to build a brand for the craft village. [6]. It is because having a brand in the market will help to consume better products, and improve workers' lives.

However, the development of the profession of making green rice flakes in the area still faces some disavantages and difficulties:

Firstly, although it has been existed for more than a century, Me Tri green rice flakes in general and Me Tri Thuong in particular have not yet had a brand of their own. Although it is the main production place, when it is sold to the market, it is still branded as Vong village green rice flakes. It can be said that compared to Vong village's green rice flakes, Me Tri's com now have more advantages and prestige such as having better taste without the use of chemicals, and it is the place that produces the most green rice flakes and finished products from them. Moreover, Vong village now has very few households producing green rice flakes, so they often buy green rice in Me Tri, bring it back for preliminary processing, and then sell it under the brand name of Vong village. Therefore, preserving the traditional processes of making green rice flakes as well as actively innovating and promoting products to gain prestige and brand name for Me Tri green rice flakes is a practical work to preserve and promote the strength of the villages and wards in particular, and of Hanoi city in general.

Secondly, the source of ingredients for making green rice flakes is not available and must be imported from other localities, so the losses from importing wet rice bagged, transportation costs, and labor are very high. Moreover, the ingredients are dependent on the weather. In the rainy and stormy seasons, damaged rice leads to high ingredient prices, affecting the production and consumption of products, typically in 2019 when a shortage of goods occurred.

Third, the profession of making green rice flakes is a hard job. Since Me Tri commune was changed into Me Tri ward, urbanization has been rapid, the fields have been shrunk and replaced by high-value apartments, office buildings, and houses for rent. Moreover, the prolonged epidemic causes the decrease in the number of households that still keeping their green rice flakes making job. Therefore, the conservation and development of the profession needs to be quickly focused.

Fourth, craft village establishments are mainly small and lack of cohesion, so it is difficult to access the capital as well as human resources who are well-trained in brand management. In Me Tri Thuong village, there is no department specialized in branding, so the promotion of products still faces many difficulties. 


\section{Nguyen Thi Hai Yen et. al/ The Profession of Producing Green Rice Flakes (Cốm) in Me Tri Thuong Village, Me Tri Ward, Nam Tu Liem District, Hanoi, Vietnam}

\section{Conclusion And Recommendation}

The profession of making green rice flakes in Me Tri Thuong village is one of the traditional professions that need to be preserved, maintained and developed. In order to do that in the future, it is necessary to:

- Have policies to encourage timely to households that still keep the profession of making green rice flakes.

- Actively build product brands to promote green rice flakes by being able to train in knowledge of brand naming to designing icons or having a system of brand identity of green rice flakes.

- Strengthen the creation of the domestic market through trade centers, supermarkets, markets, and e-commerce platforms [6],[7].

- The development of green rice flakes making profession in Me Tri craft village in general needs to be associated with tourism development by creating interesting tours to attract international visitors to visit and use the products as well as services of the craft village [8].

\section{Acknowledgements}

This study was conducted by the authors' group to serve the research topic of Department of SocioEconomic Geography and Humanities - Institute of Geography in 2022.

\section{References}

1. Nguyen Van Khoi (2012). Labor restructuring of rural households (in the case of Me Tri commune, Tu Liem district, Hanoi), Hanoi.

2. Thanh Thuy (2020). The profession of making green rice flakes in Me Tri Ha. Vietnam craft village electronic magazine, Hanoi

3. Truong Van Quang (2020), VUPPA. Maintain and protect craft villages in the process of urbanization in Nam Tu Liem District. Architecture magazine. Hanoi 2020.

4. Hanoi People's Committee (2016). Decision No. 7286/QĐ-UBND dated December 30, 2016 on the recognition of "Hanoi Traditional Craft Village".

5. https://dangcongsan.vn/tu-tuong-van-hoa/nghe-com-me-tri-duoc-cong-nhan-la-di-san-van-hoa-phivat-the- national-gia-517754.html.

6. Hanoi People's Committee (2013). Decision on approving the master plan on the development of professions and craft villages in Hanoi until 2020, with a vision to 2030.

7. Thanh Hien (2020). Hanoi craft village product branding. Need enterprise to be proactive. New Hanoi newspaper. Hanoi.

8. Hanoi People's Committee (2021). Rural industry development plan of Hanoi in 2021 (Plan No. 99/KH-UBND), Hanoi. 